\title{
Beyond the Margins: The Novel of Protest and Production
}

He wanted paper and something to write with some way to sustain a thought, place it in the world.

\section{Don DeLillo, MAO II}

The idea expressed in the quotation above, by a hostage-poet in 1960s Beirut that appears in Don DeLillo's novel MAO II, suggests the importance of writing as a way to produce new space. The narrative examines the difficult and necessary relationship between the writer, the written word, and the production of social change. In focusing attention specifically on the power of text to influence systems of oppression on a large cultural scale, MAO II provides examples of the ways in which texts record and respond to unique oppressive situations. In this way, the text functions more complexly within the space of the larger social dialectic than simply as a record of social failings. By presenting the violence of oppressive space back to the society that created it, the novel becomes an object of social protes $\mathrm{t}^{1]}$. An examination of two other novels of social protest, John Edgar Wideman's Philadelphia Fire and Sherman Alexie's Indian Killer, further illustrates the way that the book is used as an instrument of social change. These novels present arguments about the power of writing to radically expose failures of the social dialectic that, as a consequence, create new space within that dialectic.

The narrative of MAO II focuses on the reclusive writer Bill Gray. The public mystery created by his lifestyle, living in hiding with his personal assistants, keeps his image alive in popular media. The real life that he lives, behind the public myths and legends, steadily disintegrates with age and depression and alcohol abuse. As he continues to work on his "great" novel - the work that has been the focus of his entire career - the photographer Brita Nilsson, who is obsessed with capturing images of writers, visits Bill and convinces him to publish his work. Bill's novels, like 
Britta's photographs, reach thousands of individuals with intimate messages - often providing glimpses into the previously unknown and unimagined.

One of DeLillo's major concerns within the novel is to examine the power of the text and the role of the writer - to examine whether the space of the novel can create identification with the unknown or different. After Bill's publishing house sends him on a public relations tour that pulls him out of his reclusive life and, eventually, deposits him on the violent and terror stricken streets of Beirut, he confronts his own views about power, violence, and writing, as he attempts to aid the poet being held hostage by a terrorist group. The poet desires writing to save himself. The complexity of the word "save" in this context is manifest. To write, DeLillo's narrative suggests, is to rescue his sanity. To write is to render an identity other than the one he currently holds as a powerless prisoner. To write is to think. To write is to locate his self within a larger conversation of history and within the forefront of popular media. Writing to understand the world and individual identity space in the world unites both Bill's and the hostage's needs. They both see writing space as an integral social force to present ideas that might have otherwise remained inaccessible on a wider reaching scale. As Bill comments in the opening pages of the novel: "There's a curious knot that binds novelists and terrorists. In the West we become famous effigies as our books lose the power to shape and influence" (41).

While DeLillo's fictional novelist questions the potentiality of the writer to "make raids on human consciousness," the novel, as a whole, delivers an opposing argument. Bill obsesses about finishing the book he has been working on his entire career. Like the desire of the hostage to get his words onto paper, Bill's desire to get his words into print comments on the inadequacy of violent protest to create the kind of widespread protest necessary to promote change. As famous and powerful as Bill might be as a public figure, he dies alone after being struck down in a hit-andrun accident. His identification papers are stolen, and his body passes into eternity anonymously. His books and his words remain, which emphasizes the importance and longevity of books and the ideas expressed within them. Words are the tools by which we present our desires, and when we find that our desires are not being met, we are left with the empty space of disillusion - "an emptiness that words convey" (Lefebvre 97). 
Novels of social protest work to examine these empty spaces of disillusion. Writing, as representation, works as a tool of protest, because it can erase formal boundaries that in real social space create isolation and oppression. DeLillo's narrative suggests that the power of the novel comes from its ability to create unifying feelings across formal boundaries. The novel fictionalizes the kind of space about which Edward Soja theorizes in Thirdspace where the concept of binary boundaries is eradicated through "trialectical" thinking. The characters in DeLillo's novel move through dislocated and violent spaces, which force them into disillusion and into the need for words to express the threatening and unifying aspects of life. Bill's assistant Scott explains his personal experience with this unifying phenomenon upon first reading one of Bill's novels: "That book was about me somehow. I had to read it slowly to keep from jumping out of my skin. I saw myself. It was my book" (51). The power of the novel, in general terms, derives from a text's ability to make foreign problems or experiences familiar, personal and relevant. The hostage situation that Bill encounters moves him, for example, to write about the imprisoned subject for a new text. To write about the hostage captures the story to share with others, but also allows Bill an opportunity to imagine how it might feel to be in someone else's position. Sharing the disillusionment requires the ability to communicate the experience. Bill's adaptation of the poet hostage expresses the desire for understanding the product of violence and the need to share the experience with others. In expanding the horror and violent circumstances of one man's imprisonment, the hostage also stands as a textual metaphor drawing attention to a larger dialectical problem of socio-spatial imprisonment. DeLillo's novel presents a postmodern narrative spanning various cultures and geographies in order to demonstrate the kind of globalized world that Chela Sandoval in Methodology of the Oppressed describes as vital to changing oppressive space in which all citizen-subjects become "strangely permeated, transformed - and marginalized" (36). Bill's novel and DeLillo's novel highlight the space of writing to generate messages and raise consciousness, as Sandoval suggests, with an attitude toward shared understanding. The violence included in the novels performs protest by breaking into the accepted boundaries of the dialectic and forcing invisible and ignored aspects to be both seen and heard.

By examining and writing about real-world violence, through the evocation of terrorists, DeLillo's novel serves as an example of the power of the written word to reach wide audiences toward the 
development of a unifying human consciousness. The text may present violence in both physical and ideological manifestations, but the work of terrorists enacts actual instances of violence within lived spaces. The violent power of the text versus that of the violence presented by the terrorists becomes a difference between visible and invisible power. The constantly looping terrorist attacks shown on television require visibility to be effective. The invisible forces gain visibility through their acts of violence: "The hostage is the only proof that they exist" (98). The text, on the other hand, works to achieve change within the reader's consciousness through suggestion and subtle clues that must be recognized and developed. Bill considers his reasoning for writing about the hostage: "a writer creates a character as a way to reveal consciousness, increase the flow of meaning" (200). DeLillo's characters, who make their livings by creating representations, become completely drawn into violence in order to try to understand it. The characters and the text participate in the dialectic in similar ways by relying on dangerous and unknown narrative territories to create changed ideological space. Within the movement of the novel, the writer and the photographer characters are drawn repeatedly to various instances of violence occurring in different places. Brita, the photographer who begins the novel obsessed with taking pictures of writers as a way of understanding them, turns the focus of her lens on the terrorists. Capturing either subject - the writer or the terrorist - interests her as a way to understand and expose, on more than an individual scale, highly inaccessible subjects. Like DeLillo's hostage, Bill Gray maximizes his displacement by writing about it, trying to understand it, and by sharing it with others. Through protest writing, he searches for understanding and for spaces from which he will not be rejected or displaced.

DeLillo, Wideman, and Alexie all present texts concerned with the power of the novel to produce new space. One of the reasons that novels can convey protest more successfully than other approaches is by pointing to a pervasive sense of failure across boundaries in order to create change. Capturing images of defeat and other universal symptoms of loss and rejection speaks to the experiences of a wide range of people within varying spaces and spectrums of society ${ }^{[2]}$. The space of defeat, in a sense, creates a commonality that allows a greater understanding of the way space influences all. To gain support for the production of new space, the need for protest must be made clear. Fredrick Jameson suggests the advantage of using defeat as a tool in his argument for 
an aesthetic of cognitive mapping (162). Jameson argues that locations of unmappable spaces, such as the fractured global perspective at work in MAO II that cause feelings of displacement for Bill Gray, correspond to an inability to map subjectivity. Sandoval's theories further Jameson's point to suggest that trying to place the displaced subject back into a space that rejects him does not reflect the postmodern way of thinking. Instead, Sandoval argues that the neocolonizingpostmodern world produces differential social consciousness ${ }^{[3]}$ as an important mode of resistance to the pressures of oppression (179). DeLillo's characters endlessly struggle in the alienated and invisible positions associated with their dislocation. Charlie, the chairman of a "high-minded committee on free expression," suggests the necessity of a writer's influence when, regarding the hostage's status, he asks Bill: "How do you create a shift in rooted attitudes and hard-line positions if not through public events that show us how to imagine other possibilities?" (98). The novel successfully conveys protest to the socio-spatial dialectic by representing the damaging status of the exile position and the pervasive sense of failure to achieve changed spaces.

Wideman's novel Philadelphia Fire focuses specifically on violence and protest within the sociospatial dialectic of the urban ghetto. The novel provides a postmodern narrative that illustrates Soja's concept of trialectics at work by presenting an-Other way of thinking about the production of social space: Wideman's narrative exposes the failures of the dialectic from the marginalized point of view. The novel specifically examines the difficulties that marginalized individuals experience when they try to influence large-scale social chang $\mathrm{e}^{4]}$. An exile-writer, Cudjoe, leads the reader through the fragmented narrative. He explains in third-person-style that he cannot "account for the force drawing him to the story nor why he indulges a fantasy of identification with the boy who escaped the massacre" (8). As MAO II questions the ways that ideology and fragmented space can keep one in a continual state of imprisonment and alienation, Philadelphia Fire examines the oppressive physical and ideological landscape of urban space to help answer the complex question that Cudjoe, poses: why?

The lost boy who draws Cudjoe home is displaced by a central moment of violence. The politically sponsored firebombing of the protest organization MOVE's house in an urban 1980s Philadelphia neighborhood provides the common thread throughout the narrative. The fire in Philadelphia that Wideman's novel concerns itself with, however, is not limited to the bombing of the MOVE house. 
Rather, the text focuses on the institutions that exist within the urban experience that contribute to such violence. The fire represents various locations of social space - fragments suggested by Lefebvre that define space - within the ghetto that inform subjectivity. The characters and events that Wideman presents weave throughout fact and fiction and time, illustrating the connectedness of all stories and problems relevant to the human experience. Cudjoe leads the investigation of the firebombing with the intention of writing a book about the event to, as he comments, "do something about the silence" (19). His investigations connect him with the inhabitants of the bombed neighborhood, who experienced the violence and oppression of the city first hand, as well as the political figures and the power structures responsible for the bombing and oppression. Ultimately, like DeLillo, Wideman allows the protest to be performed by the novel by examining acts of social protest both in physical and textual terms. The space of the novel and the role of the writer are then exposed as vital to the creation of changed social space.

Cudjoe and Wideman, as narrators, both occupy positions as exiles, because of their positions within oppressive urban landscapes. To establish the relationship between place and subjectivity, the novel begins with the story of an exile as the ultimate product of the urban ghetto. Zivanias, the captain of a ship in Greece, is swallowed up by a sea storm leaving "never a trace" (5). Although Wideman never refers directly to this character again, Zivanias sets the premise for the words and stories to follow. The novel protests the oppressive forces that create exiles that, like Zivanias, have fallen off the edge of the world, by recording and passing on their stories. Wideman leaves Zivanias' trace forever in the text. He uses the power of the novel, and the intention of the storms their words might usher in, to create new ways of thinking and seeing. Cudjoe, as narrator, shares Zivanias' position of isolated life on the Greek island, as he says, "I became an institution... Part of the island... Everybody loved me. Then forgot me. Invisible man" (87). The image of the invisible man, a harkening to Ralph Ellison's black urban Invisible Man, reinforces the status of the urban dweller as a placeless individual and connects that concept with the idea that place and subjectivity form an intimate and vital relationship. Cudjoe might consider himself part of the island, but he feels lonely most of the time (87). He feels homeless both in the city and out of it. The text searches for lived spaces, and, as it fails in Jamesonian terms to find any adequate mappable 
space of self-definition, the novel continues searching and moving toward the production of new space for occupation.

Cudjoe can never be a fully functioning part of the island, because he finds himself there simply as a lost child produced by the city. Nor can he ever be a fully functioning part of the city, because he exists there on the margins - pushed out by the power structures that constantly contribute to his sense of oppression and fragmented identity. The protests carried out within the pages of Philadelphia Fire respond to what Lefebvre calls an inability to adapt within the communal environments created by others. The failures of which, then, teach us how to create new space (Lefebvre 166). Wideman's novel aims to stop the production of exiles by reconciling identity with space. This process - the production of new social space - as Wideman's text illustrates, is difficult and often very dangerous. Like MAO II, Wideman's narrative examines the novel as a powerful tool of representation and the process of writing as a way to understand and reconcile fragmentation. Wideman's characters exist within the oppressive invisible landscape of the dialectic, which provides them with a powerful vantage point from which to create new space.

The Kiddie Krusade, a fear-based protest group appearing in Philadelphia Fire, serves as an example of the way ideas can be promoted through textual messages and representation. By projecting their theories through writing, the group remains safely behind the mask of anonymity. The Kiddie Krusade speaks for the younger generation with aspirations for gaining both social and economic equality. The group appears to hold a radical position, but their demands simply reflect the American dream construct inherent in the landscape surrounding them. Cudjoe calls the work of the Kiddie Krusade "inflammatory propaganda," but, like the space of the novel itself, the aim of the protest is to "spread the word" (90). Just as the Kiddie Krusade's messages are only as powerful as the effects that they create within their landscape, so too is Wideman's novel only as successful as its creation of new space within the minds of its readers. The potential power of protest found within the written word becomes lost in the textual messages presented by the Kiddie Korps because their protest relies on a misunderstanding of the importance of power already at work in their social space: the desire to obtain money, power, and things. The power of text cannot help the Kiddie Krusade to create new space because they are working to attain oppressive social constructs. 
By rewriting history and offering exiles alternative spaces for occupation, Philadelphia Fire appropriates the power of the text, not as propaganda, but as protest. The novel creates new descriptive spaces that challenge existing boundaries by weaving together fact and fiction and by using multiple narrators and locations. The fictional character who escaped the firebombing of the MOVE organization house, created by Wideman, "is the key," because he opens up larger discussions about exiled sons in general (88). The destruction of one neighborhood in Philadelphia becomes a giant metaphor for the mass exile of black American youth and culture within the oppressive urban landscape. The metaphor extends into a critique of the larger workings of the systems at hand through the narrator's own exile from his life in the urban community. The narrator, considering the Kiddie Korps and the problems of the city, comments:

Don't care how dry the straw is and how high it's heaped in the barn, you still need a match.

To light the fire.

Light the fire. (91)

Writing as insurrection acts upon the narrator's last two lines. The text is the match and the reader, ostensibly, is the one who controls the ignition. The text acts as the catalyst to evoke change because it provides the instruction to the reader to take action. Wideman suggests that, even with the information he provides, creating new space within the dialectic will fail without participation.

Wideman's writer, like DeLillo's, gets drawn into violent spaces in an attempt to understand them just as DeLillo and Wideman, as writers of novels themselves, examine and define violent spaces in an effort to generate understanding and change. One factor that presides heavily within both texts is the concept of the power of a text to provide a voice for the silenced figure historically, socially, and spatially. Literary theorist Terry Eagleton comments on the necessity for representations of violent social space:

We live within societies whose aim is not simply to combat radical ideas - that one would readily expect - but to wipe them from living memory: to bring about an amnesiac condition in which it 
would be as though such notions had never existed, placing them beyond the very powers of conception. (qtd. in Bibby 150)

Sherman Alexie's novel Indian Killer aims to subvert the paradigm of silence that Eagleton describes. The narrative questions identity formation for the marginalized American Indian figure in several ways. Alexie presents John Smith, an American Indian adopted by a white family. John struggles to form his own identity in the face of rampant misrepresentation of Native people by white society. This tension also divides him from his white parents and leaves him feeling even more alone, which further signifies the displacement of the marginalized figure. Alexie shows the damaging legacy of historical and academic representations of Indians as savages and other negative characterizations. He also uses the public response to serial killings that not only name the murderer The Indian Killer, but, in so doing, create a wide spread panic of violent attacks against Native people. Alexie's narrative complicates the term Indian Killer through double meaning. While the surface meaning refers to a serial killer who murders and then scalps his victims, the white misappropriation and representation of native culture, in essence, also kills the Indian. Much critical debate questions the identity of the murderer, which Alexie's narrative never reveals or names. This ambiguity argues that the point of the novel is to reveal that the killer is not a single man wrapped into a simple identity. The killer is the complex and largely ignored legacy of an American culture rising from the genocide of thousands of Native people.

Alexie crafts a novel, like Wideman's, that represents fictional violence as a tool of protest to real oppression in an attempt to create new space. While Philadelphia Fire's exile returns to his roots to save other lost children of the landscape with stories and words meant to rebuild the space historically, geographically, and conceptually, Indian Killer's exile will never find or produce a space within which to return. Alexie's novel enters a dialectic that, for the Native American, is broken beyond reparation. Common historic and literary depictions of the Native subject inform the dialectic and the subjectivity of the American Indian negatively - still harboring characterizations of the savage and the wild. The physical space occupied by the Native American, as well, creates a divide, because reservation space exists on the extreme margins. Alexie's novel illustrates that mappable geographic locations for return, for rehabilitation, or even for production, do not exist as tangible locations of protest within the contemporary narrative of the Native American. Not only 
does the postmodern landscape for Native people present the Jamesonian dilemma of unmappable spaces upon subjectivity, Alexie's novel argues, as well, that the only hope in the postmodern world for the production of new space is to make sure we never repeat the failures that he identifies. The novel ends with the main character, John Smith, jumping from the heights of the last skyscraper being constructed in Seattle to the dark urban streets below. Either on or off the reservation, he finds no spaces to occupy. He has no place to relocate his identity for selfdefinition. The space of the novel becomes a representation to provide, as Wideman's text also does, evidence of the failure of the dialectic. Indian Killer aims not to produce new space for the exiled Native American, but to represent the ways in which the dialectic fails him - making the production of new space impossible. The novel gives a voice to the Native American, arguing for the importance of speaking for and of representing onesel[f].

The novel locates the power to create change in the written word through examples of historical and fictional representations of Native Americans. Marie, a Native university student, continually fights against white accounts of her culture. Alexie highlights the difficult nature of the task, because both Marie and her cousin Reggie are unable to make the differences that they view as necessary. Both Marie and Reggie are alienated from their tribal communities because they were successful in white educational systems. Marie remembers that she was not allowed to learn the tribal language or stories of history because her family did not want her to remain on the reservation. The family viewed education and a life outside of the reservation as a better option for a more promising future. What Marie and Reggie find, outside of the reservation, are more forms of alienation. Their exile status from reservation space and heritage, much like John Smith's status, is reinforced by the misrepresentation of their history and identity as Native people in the educational and social systems. Although they all try, none of the Native characters find adequate power to revise the oppressive constructions. Even Wilson, a white novelist posing as a Native American, points to the problem of misrepresentation: "But it was a lie. Wilson knew about liars and what the TV and movies said about Indians were lies" (158). Although he is aware of the problem, Wilson continues to contribute to the false accounts of Native life in his white-centered and popularly read publications. Marie and Reggie exemplify the voiceless position and cannot address misrepresentations and lies that continually violate their subjectivity. Alexie aims to break into this 
violating conversation, to gain audience for the message, and to provide a new way of seeing and believing.

John, Marie, and Reggie, and the various urban Indian street-dwellers introduced throughout the novel, find themselves without tribes and without a sense of home. Their attempts at resistance to white forces go largely unnoticed. Power, as Lefebvre remarks, "aspires to control space in its entirety" through grids and formations intended to divide and rule (388). The novel's Native figures are so fully displaced by the power structure that they find themselves without any space to inhabit. Marie, in response to this situation, turns her protest attentions to the misrepresentation that has created such a sense of exile for her own people. She organizes boycotts, rallies, and sit-ins on the university lawn to raise awareness about the appropriation and misrepresentation of Native Americans by whites - to fight the lies. Marie knows that paying attention to the problem of homelessness, which she spends much of her time doing, is more important than trying to find ways to ignore it. She delivers food to the displaced, because she knows that many of them "waited for the food, for the company, for proof that they were not invisible" (146). By acknowledging and addressing the problem, Marie subverts the common attitude of the majority to ignore or hide away problems and differences. Her efforts to create tangible change by these means occur on a small and limited scale. The systems of power allow Marie's protests to continue, because she does not pose a viable threat. When her attempts become more forceful she openly disagrees with her white professor about the way he teaches Native American literature - the university administration silences her. She wonders if she seeks education "just because she was looking for revenge" (147). But her acts of rebellion cannot achieve the creation of new space about which Soja and Lefebvre theorize because the dominant forces limit the scope of her acts through her access to the power of language. She cannot break out of the binary boundaries that exist in her social system because, as Alexie's narrative illustrates, white culture has killed the Native American, both historically and culturally.

The idea of white books murdering Indian books stirs up violence in Marie and in Reggie for revenge against their oppressor. Just as Marie's and Reggie's vocalizations of dissent are quickly struck down by the power holders, the attention that the Indian Killer murderer attempts to draw to the inequality of Native people is quickly subverted by a violent backlash from the majority. The 
killings, as a mode of protest, do not work to successfully create change. The novel illustrates that revenge-fueled actions simply create more violence. Marie's attitude of revenge is clear: "She wanted every white man to disappear. She wanted to burn them all down to ash and feast on their smoke. Hateful, powerful thoughts. She wondered what those hateful, powerful thoughts could create" (85). Marie knows, as does John, that drastic acts must be taken in order to achieve awareness and change. Her rage with the white power structure exists as an imaged response rather than something she might one day realize. John also knows that he could "kill a thousand rich white men and not change a thing" (28). The murders cannot be effective tools to create change because the violence they enact is already understood within the framework of the space in which they occur. The violence of the revenge murders does not provide a catalyst for change; instead, the violence simply creates more negative responses within the social space.

Rather than present a manifesto promoting violence against white society, Alexie's novel connects, as Marie's statement suggests, the power of thought with the power of protest. The novelist, like the Indian Killer, acts as an invisible force behind the action. The actions of the characters and the aggressive racist propaganda response serve as examples to argue the point that violence for any reason never solves a problem and usually just creates more conflict. By using fictional violence connected to an unknown serial killer to gain attention for the problems, Alexie suggests that often the most important point is not finding the right answer, but asking the right questions. In response to the white novelist, Wilson, who asks whether or not a real Indian would commit the brutal murders, Reggie says:

I think an Indian could do something like that. Maybe the question should be something different. Maybe you should be wondering which Indian wouldn't do it. Lots of real Indian men out there have plenty enough reasons to kill a white man. Three at this table right now. (184)

Presenting the murders through an always anonymous figure allows Alexie to suggest the equal capability within us all to commit acts of violence against one another. Many readers fall into a trap of the detective story and get lost in the narrative trying to figure out the identity of the murderer. The text provides a more basic and perhaps important question: Why would rebellious murders like these occur? The novel delivers several examples of murder to help the reader consider this 
question. A white college student named David is found dead at an Indian casino. The easy and popular response that the narrative illustrates is to go out and attack Native Americans to avenge David's murder. The motivation for David's murder is linked not with Native culture but with white petty thievery and drugs. The difficult task, the novel shows, is to examine the situation - to peel back, to analyze and to change, the layers of social, political, economic, and geographic structures that might motivate the murder of one boy or the genocide of millions of people.

In Bloodscripts, the critical text on the violent subject, Elana Gomel points out that "the actual incidence of serial killing remains small compared to the other kind of violent crime, the literature on the subject is enormous" (34). Alexie's novel plays with the idea of obsession with serial killings by illustrating the crazed reaction of the general public to the murders. At the same time, the novel emphasizes the various other invisible moments of violence occurring. Alexie's novel represents violent spaces of murderous revenge to position the reader as detective - as a vital tool within the protest that the text has the power to perform - to achieve recognition for the devastating and largely ignored legacy of genocide and oppression of Native peoples at the hands of the American government and to, in turn, create new historical space for accurate representation from Native perspectives. The novel leaves the reader questioning what other choice John might have but to jump off of a building - where else would he go?

MAO II, Philadelphia Fire, and Indian Killer use the space of the novel to examine the culpability of us all within the socio-spatial dialectic. The writer and the reader, alike, share responsibility for John Smith's fall, for the MOVE bombing, for the plight of the hostage-terrorist and for all of the oppressive spaces that these fictions represent. The novels also argue that we share the responsibility to create change - to light the match or to start the storm. Wideman's narrator tells us that we have the power "to do what no one can do for you [...] We do have a chance to unfold our days one by one and piece together a story that shapes us" (151). Similarly, the firebombing of a house on Osage Avenue in Philadelphia begins another storm. A storm of the text - the power of the word - to record the story. To pass on the story. To keep at least a trace. When Wideman's narrator makes the statement, "Imagine our fictions imagining us," he suggests a bold vision for the potential power of the novel (98). The fiction that Wideman creates in Philadelphia Fire questions the dominant perception of reality, but the novel also suggests that the audience of the text re- 
imagine reality as well. When he meets with a survivor of the bombing, Margaret Jones, to interview her about the fire and to try to find out some information about the missing boy, Simba, Cudjoe explains his motivation for writing the book as trying to do "something about the silence" (19). The silence with which Cudjoe, and Wideman, concern themselves arises out of the problem of protesting a situation in which the participants do not recognize progress toward change:

So what's different now? Maybe nothing, Cudjoe. I wonder why we ever believed it was spozed to get better. Who fed us that lie? Why'd we swallow it? What's different? Something ought to be, shouldn't it? (77)

Jones suggests that people need to view the damage of the fire first hand. She suggests that to understand the devastation and the situation in real terms, people must visit the actual location. The underlying problem with her point is that the specific site of violence that she talks about is inaccessible to the average person and to a wide audience. To bring the fire home, to locate it personally, Wideman captures the various stories and feelings within the pages of the text. He also capitalizes on the universal concept of disillusionment to appeal to a broader audience.

DeLillo, Wideman, and Alexie present protests to the socio-spatial dialectic from different perspectives and for varying reasons. What the texts share is the promotion of the novel as a vital space of violent protest. The power of textual representation assumes the position of the match waiting to start the fire. These texts recognize the need for a sudden a war - a fight to reclaim lost boys and to create new spaces in which to bring them home. "Hold on," the narrator pleads in Philadelphia Fire, "I cannot separate myself from you. Yet I understand we're different" (151). Novels like DeLillo's, Wideman's and Alexie's reflect the systems - in all of the horrors - back to themselves and to the participants. "Suddenly this is a war," the narrator of Indian Killer states, after John's adoption into a white family. To illustrate the damaging effects of such actions, like removing Native children from their cultural heritage, Alexie creates a fantasy-moment in which gunfire rains down on a crowd of Native people. The Indians stand unfazed. They are so accustomed to being attacked that they offer no reaction. These novels, similarly, expose the reader to the bullets raining down upon helpless individuals, and in the presentation they ask us to 
consider whether we are willing to stand behind the gun - or, if, instead, we might move to change our perspectives and to create changed spaces in our systems.

\section{Works Cited}

Alexie, Sherman. Indian Killer. New York: Warner, 1996.

Bibby, Michael. "Insurgent Poetry and the Ideology of the Poetic." Poetics/Politics: Radical Aesthetics for the Classroom. Ed. Amitava Kumar. New York: St. Martin's P, 1999. 135-154.

DeLillo, Don. MAO II. New York: Viking, 1991.

Gomel, Elana. Bloodscripts: Writing the Violent Subject. Columbus: Ohio State UP, 2003.

Jameson, Fredric. "Cognitive Mapping." Poetics/Politics: Radical Aesthetics for the Classroom. Ed. Amitava Kumar. New York: St. Martin's P, 1999. 155-171.

Lefebvre, Henri. The Production of Space. Oxford: Blackwell, 1991.

Redding, Arthur. RAIDS on Human Consciousness. Columbia, SC: U of South Carolina P, 1998.

Sandoval, Chela. Methodology of the Oppressed. Minneapolis: U of Minnesota P, 2000.

Soja, Edward W. Thirdspace: Journeys to Los Angeles and other Real-and-Imagined Places.

Cambridge: Blackwell, 1996.

Wideman, John Edgar. Philadelphia Fire. New York: Vintage, 1991. 
[1] In The Production of Space, Lefebvre notes that, although the reflection of space can be full of dangers and black holes, it also presents opportunity full of "sequences, sets of objects, concatenations of bodies - so much so, in fact, that anyone can at any time discover new ones, forever slipping from the non-visible realm into the visible, from opacity to transparency" (183). [2] Arthur Redding, in his text Raids on Human Consciousness, comments on the need to communicate suffering in order to create change:While suffering cannot be accurately communicated, it is what necessitates communication per se. Because you cannot know my suffering, because you are not me, I am compelled to explain it to you, to bridge the gap between self and other, to work by whatever means necessary to overcome the pain. Because suffering above every other affect or idea - is what cannot, phenomenologically, be presented to another individual and is, by that same token, what needs most urgently to be presented in order that an end be made of pain, we are thrown into the dilemma that is not simply tragedy but representation itself. (18-19)

[3] To deploy a differential oppositional consciousness, Sandoval writes, "one can depend on no (traditional) mode of belief in one's own subject position or ideology; nevertheless, such positions and beliefs are called up and utilized in order to constitute whatever forms of subjectivity are necessary to act in an also (now obviously) constituted social world" (31). To attain power over the traditional and the now and at the same time to be neither is the power of differential consciousness.

[4] A comparison of dominant and subordinate narratives is so important to an investigation of the spatial dialectic and identity formation because it acknowledges that oppression exists across lines of race, class, and gender. The comparison also makes evident that marginalized individuals, because of their position outside of the dialectic, ultimately have the vision and the power to take control and to repair their sense of self. Marginalized subjects stop trying to create a unified version of the self as reflected by an incongruous socio-spatial mirror. Instead, these characters realize they must imagine and construct their own identity spaces of reflection.

[5] Just as Sandoval warns about the dangers of systems of oppression to prescribe, the white versions of Native experience most often codifies the behavior, turning it into a mythology of the 
perpetuation of oppression rather than a strategy of redemption or revolution. Alexie's Native characters participate in what Sandoval sees as integral to differential consciousness: the "reappropriation of ideology insists on the ability of consciousness to meta-ideologize, to move in, through, and outside of dominant ideology..." (112).

\section{(c) (i) (9)}

Creative Commons Attribution-NonCommercial-NoDerivatives 4.0 International License 